\title{
The clinical association of programmed cell death protein 4 (PDCD4) with solid tumors and its prognostic significance: a meta-analysis
}

\author{
John Zeng Hong $\mathrm{Li}^{1+}$, Wei Gao ${ }^{1+}$, Wai-Kuen Ho${ }^{1}$, Wen Bin Lei ${ }^{2}$, William Ignace Wei ${ }^{1}$, Jimmy Yu-Wai Chan ${ }^{1}$ \\ and Thian-Sze Wong ${ }^{1 *}$
}

\begin{abstract}
Background: Programmed cell death protein 4 (PDCD4) is a novel tumor suppressor protein involved in programmed cell death. Its association with cancer progression has been observed in multiple tumor models, but evidence supporting its association with solid tumors in humans remains controversial. This study aimed to determine the clinical significance and prognostic value of PDCD4 in solid tumors.

Methods: A systematic literature review was performed to retrieve publications with available clinical information and survival data. The eligibility of the selected articles was based on the criteria of the Dutch Cochrane Centre proposed by the Meta-analysis Of Observational Studies in Epidemiology group. Pooled odds ratios (ORs), hazard ratios (HRs), and 95\% confidence intervals (Cls) for survival analysis were calculated. Publication bias was examined by Begg's and Egger's tests.

Results: Clinical data of 2227 cancer patients with solid tumors from 23 studies were evaluated. PDCD4 expression was significantly associated with the differentiation status of head and neck cancer (OR 4.25,95\% CI 1.87-9.66) and digestive system cancer (OR 2.87, 95\% Cl 1.84-4.48). Down-regulation of PDCD4 was significantly associated with short overall survival of patients with head and neck (HR: 3.44, 95\% Cl 2.38-4.98), breast (HR: 1.86, 95\% Cl 1.36-2.54), digestive system (HR: 2.12, 95\% Cl 1.75-2.56), and urinary system cancers (HR: 3.16, 95\% Cl 1.06-9.41).

Conclusions: The current evidence suggests that PDCD4 down-regulation is involved in the progression of several types of solid tumor and is a potential marker for solid tumor prognoses. Its clinical usefulness should be confirmed by large-scale prospective studies.
\end{abstract}

Keywords: Programmed cell death protein 4 (PDCD4), Solid tumor, Meta-analysis, Prognosis, Overall survival, Disease-free survival, Recurrence-free survival

\section{Background}

Programmed cell death protein 4 (PDCD4) is a novel tumor suppressor protein involved in programmed cell death. The PDCD4 gene is located on chromosome 10q24, and its allelic loss/gain is frequently reported in human cancers. Up-regulation of PDCD4 is observed after the initiation of apoptosis, suggesting that loss of,

\footnotetext{
*Correspondence: thiansze@gmail.com

${ }^{\dagger} J$ ohn Zeng Hong Li and Wei Gao contributed equally to this work

1 Department of Surgery, The University of Hong Kong, Queen Mary

Hospital, Hong Kong, Hong Kong, SAR, P. R. China

Full list of author information is available at the end of the article
}

or reduced, $P D C D 4$ expression could contribute to the anti-apoptotic property of cancer cells [1]. In mouse epidermal JB6 cells, which are resistant to anchoragedependent cell death and neoplastic transformation, high levels of PDCD4 expression could be induced in response to the presence of tumor promoters such as 12-O-tetradecanoylphorbol-13-acetate [2] and tumor necrosis factor-alpha [3]. Therefore, it has been suggested that PDCD4 is a potent tumor suppressor gene. PDCD4 could inhibit neoplastic transformation through inhibition of adaptor protein-1 (AP-1) activation [3]. Structurally, PDCD4 could interact with RNA helicase eukaryotic 
translation initiation factor 4A (eIF4A), inhibiting its helicase activity and affecting protein translation $[4,5]$. In addition, PDCD4 could inhibit nuclear factor kappaB (NF-kB)-dependent transcription and related pathways [6].

Loss of important tumor suppressors with critical functions during the transformation process is a hallmark of cancer. Identifying key tumor suppressor proteins is important for the sub-classification of tumors at different stages with different behaviors. Moreover, the elucidation of the pathways associated with tumor suppressors could help identify predictive markers for prognostic use and provide novel insights into cancer treatment. Accumulated results in preclinical studies indicate that $P D C D 4$ is a novel tumor suppressor gene with anti-neoplastic properties [7-9]. Nevertheless, some studies have suggested the conflicting conclusion that PDCD4 does not exert a tumor-suppressing effect in certain malignancies, such as non-small cell lung cancer $[10,11]$. To explore whether PDCD4 consistently acts as a tumor suppressor and positive prognostic marker for solid tumors, we conducted an updated meta-analysis to evaluate the clinical significance and prognostic value of PDCD4 in human cancers.

\section{Methods}

\section{Literature search}

A systematic literature search through PubMed, EMBASE, and MEDLINE was performed using the following main keywords: "PDCD4" and "cancer" or "carcinoma" or "tumor" or "malignancy." All studies that examined the expression status of PDCD4 were recruited regardless of the detection methods used. The last search was performed on January 12th, 2016.

\section{Study selection}

Two reviewers (JZHL and WG) manually screened and selected the eligible studies independently. Studies that were not reported in English or Chinese, review articles, studies that had used cell lines and animal models without any data on human tissue samples, and studies without sufficient data for calculation were excluded from the analysis.

\section{Methodology quality assessment}

The studies on prognosis were evaluated using the criteria of the Dutch Cochrane Centre proposed by Metaanalysis Of Observational Studies in Epidemiology (MOOSE) group [12]. The following inclusion criteria were used: (1) trial dealt with PDCD4; (2) clear definition of study design; (3) clear definition of outcome assessment, including overall survival (OS), disease-specific survival (DSS), disease-free survival (DFS), and relapsefree survival (RFS); (4) clear definition of cut-off score of PDCD4 expression or high/low evaluation; and (5) a follow-up period of at least 12 months.

\section{Data extraction}

The selected publications were accessed by two reviewers (JZHL and WG). The following details were retrieved from the selected papers: (1) general information, including the first author, publication year, case populations, cancer types, sample types, and test methods; (2) the case number in each of the sub-groups with different PDCD4 expression levels and diverse clinicopathologic properties; and (3) the results of survival analysis, including hazard ratios (HRs) and 95\% confidence intervals (CIs).

\section{Statistical analysis}

Pooled odd ratios (ORs), HRs, and 95\% CIs were calculated for the evaluation of the clinicopathologic association of PDCD4 and its prognostic value in solid tumors. To check whether there was homogeneity among the individual ORs/HRs for the selection of the optimal effects model analysis, a heterogeneity test with the inconsistency index $\left(I^{2}\right)$ statistic and $Q$ statistic ( $P$ value) was performed. Substantial heterogeneity was indicated when $I^{2} \geq 50 \%$ and $P<0.05$, and a random effects model was adopted; a fixed effects model was appropriate when $I^{2}<50 \%$ and $P>0.05$. After a suitable model had been chosen, Forest plots with pooled OR/HR and 95\% CIs were then retrieved from the individual HRs and 95\% CIs. Pooled OR/HR $>1$ suggested that the worst prognoses were more likely to occur in the patients with no, or low levels of, PDCD4 expression than those with high levels of PDCD4 expression. Statistically significant differences between groups with diverse PDCD4 expression levels was determined if the $95 \% \mathrm{CI}$ did not overlap 1 . In addition to the calculation of overall OR/HR and $95 \%$ $\mathrm{CI}$, subgroup analysis was performed with respect to the case population (Asian/European/North American), cancer type (brain tumor/head and neck cancer/breast cancer/digestive system cancer/respiratory system tumor/ gynecologic tumor/urinary system cancer), and sample type (protein/RNA).

Publication bias was assessed by the Begg's and Egger's tests [13]. $P<0.05$ represented a statistically significant publication bias. All analyses were performed with Stata software version 12.0 (Stata Corporation, College Station, TX, USA).

\section{Results}

\section{Study characteristics and qualitative assessment}

According to the selection criteria, 493 articles were found in the initial screening. After removing 445 irrelevant articles, 33 articles were selected for further evaluation. According to the critical checklist of the Dutch 
Cochrane Centre, 23 articles fulfilled all of the quality assessment criteria. These 23 articles, involving a total of 2227 solid tumor cases, were included in the meta-analysis. Figure 1 shows the selection process. The characteristics of the included studies are shown in Table 1.

\section{Associations of PDCD4 down-regulation with the clinicopathologic parameters of cancer patients}

The associations between PDCD4 expression and the clinicopathologic features of patients with solid tumors are shown in Table 2. Four studies of digestive system cancers $[7,14-16]$ and one study of urinary system cancers [17] examined associations between tumor size and PDCD4 expression level. All of the studies were carried out on Asian patients using antigen-based methods, and the combined OR indicated no significant association. Low PDCD4 expression level was associated with advanced $\mathrm{T}$ category of urinary system cancers (OR 4.87, 95\% CI 1.69-14.00) [17] and head and neck cancers (OR 2.15, 95\% CI 1.10-4.19) [18]. However, PDCD4 expression level was not associated with the $\mathrm{T}$ category of digestive system cancers (OR $0.98,95 \%$ CI $0.46-2.08$ ) [15, 19]. There was no obvious evidence for an association between PDCD4 expression and the N category of head and neck cancers $[20,21]$, respiratory system cancers [22], and digestive system cancers [7, 15, 19, 23]. Low PDCD4 level was associated with advanced M category of urinary system cancers (OR 4.87, 95\% CI 1.69-14.00) [17] and advanced clinical stage of head and neck cancers (OR 2.30, 95\% CI 1.44-3.69) [18, 20, 21, 24].

Low PDCD4 expression was significantly associated with advanced stages of head and neck cancers (Fig. 2a). Low PDCD4 level was associated with moderately/poorly differentiated head and neck cancers (OR 4.25, 95\% CI

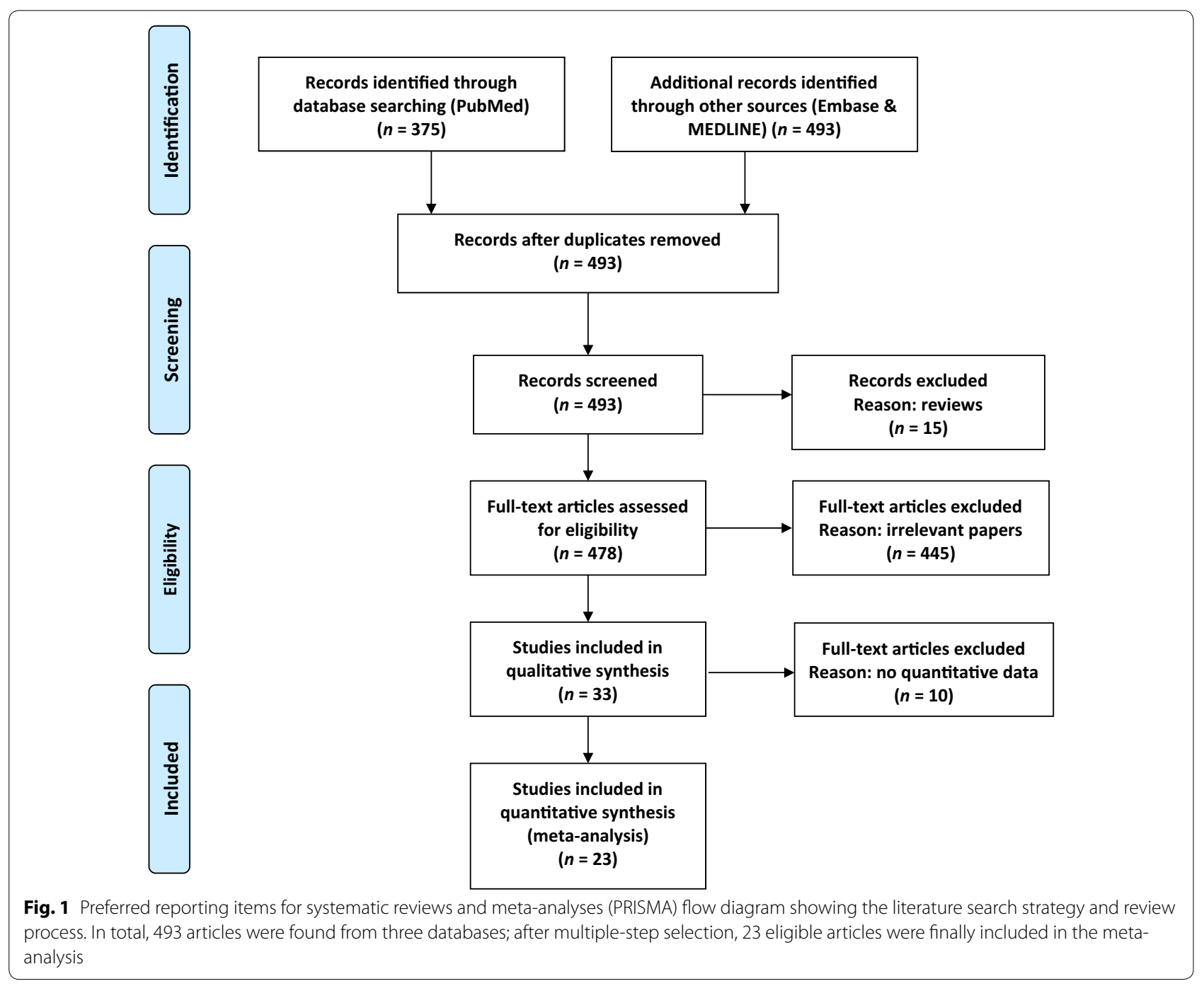




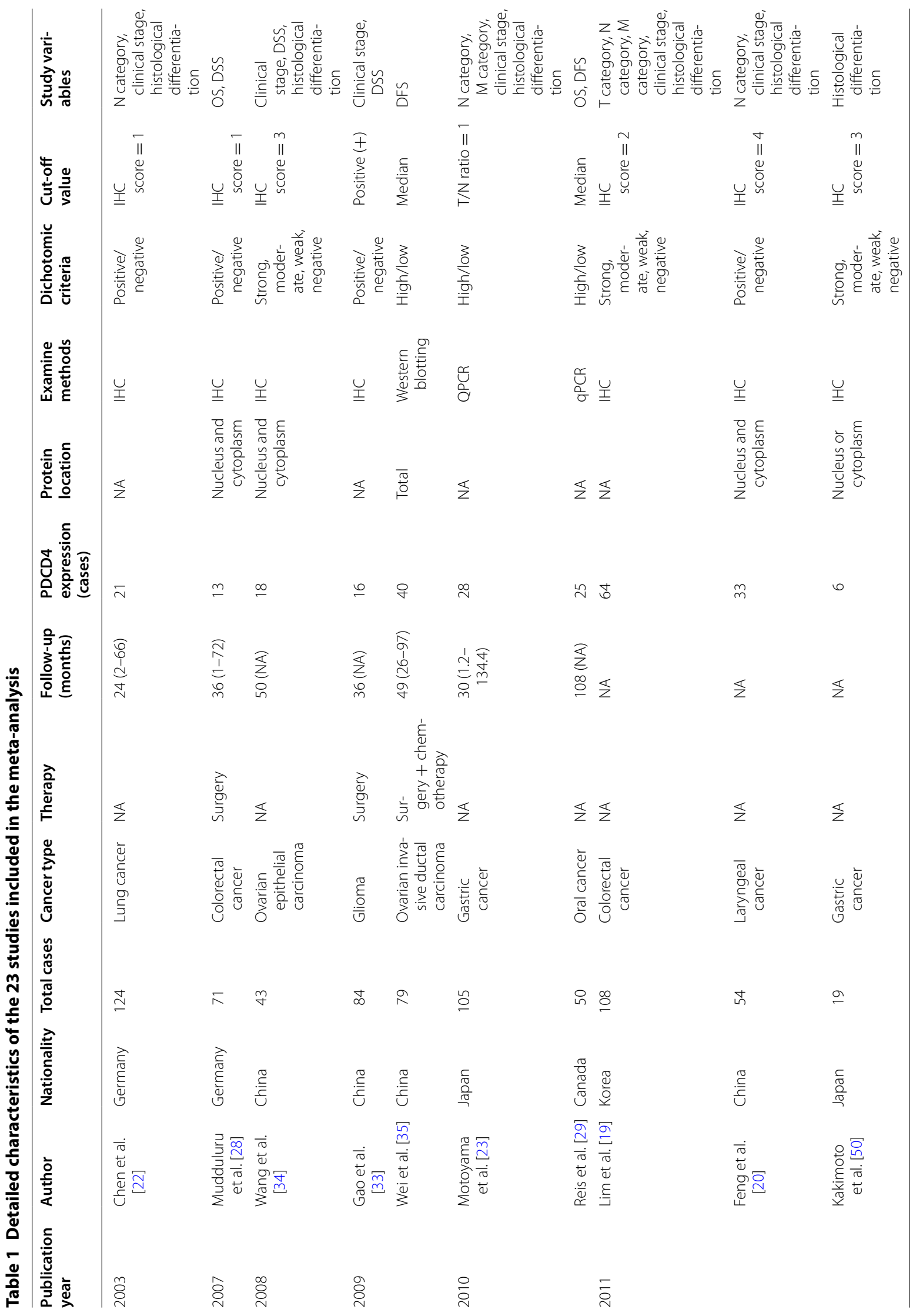




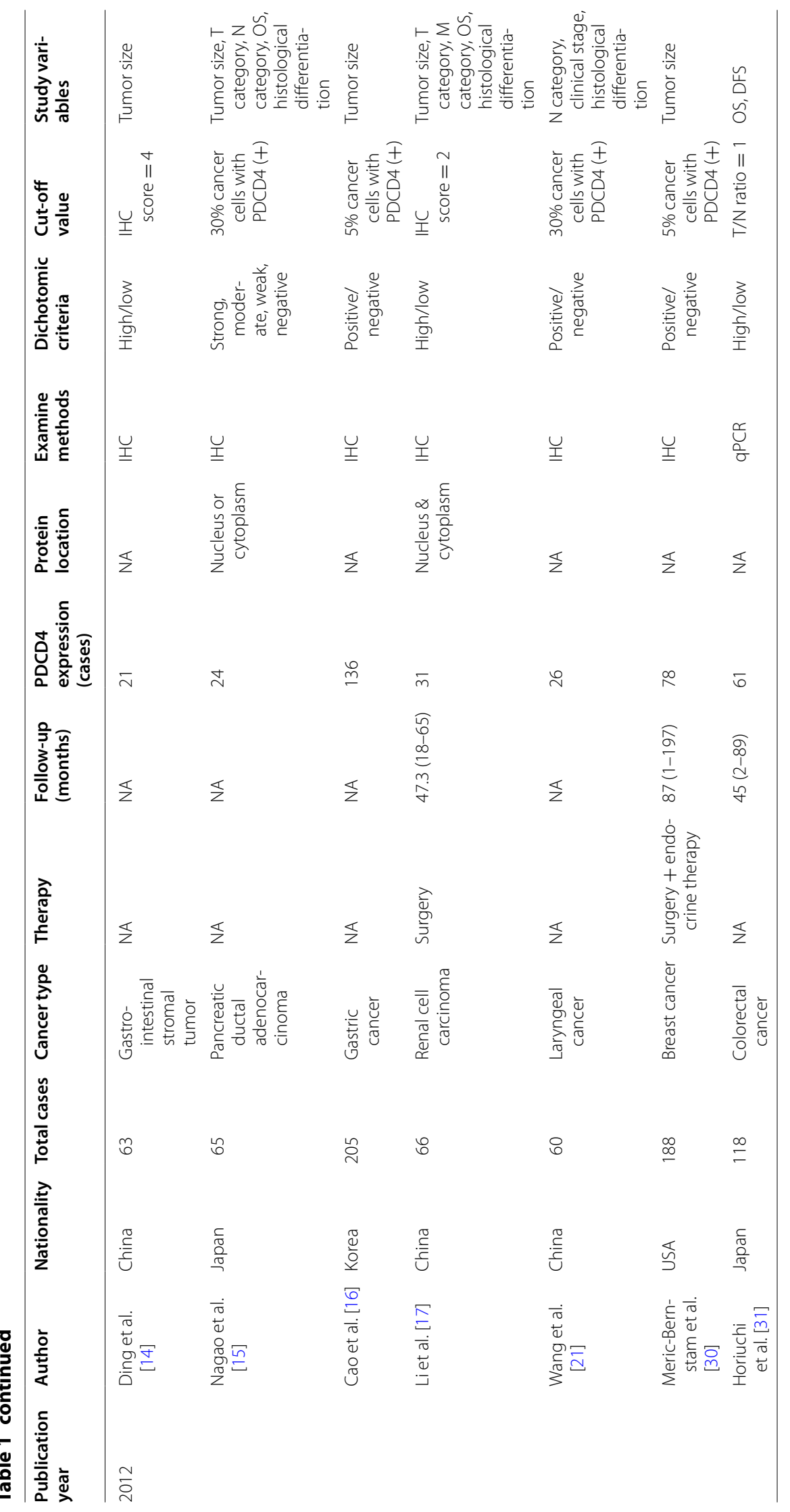




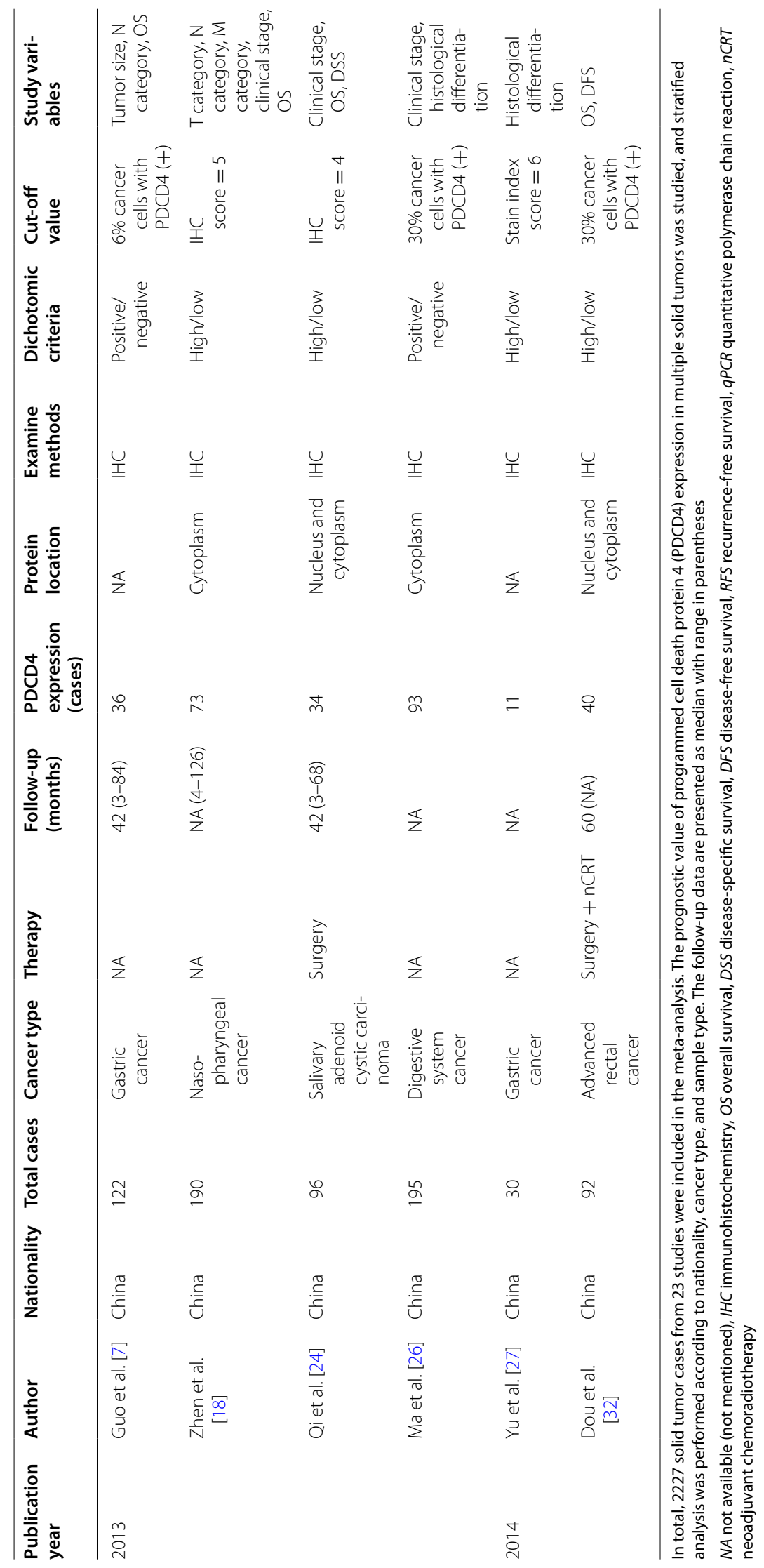


Table 2 Associations between PDCD4 down-regulation and the clinicopathologic parameters of patients with solid tumors

\begin{tabular}{|c|c|c|c|c|c|c|c|c|c|}
\hline \multirow[t]{2}{*}{ Parameter } & \multirow[t]{2}{*}{ Study subjects } & \multirow[t]{2}{*}{ Reference(s) } & \multirow[t]{2}{*}{ Total cases } & \multicolumn{2}{|c|}{$\begin{array}{l}\text { PDCD4 expression } \\
\text { (cases) }^{\mathrm{a}}\end{array}$} & \multirow[t]{2}{*}{ OR } & \multirow[t]{2}{*}{$95 \% \mathrm{Cl}$} & \multirow[t]{2}{*}{$I^{2}(\%)$} & \multirow[t]{2}{*}{$P$} \\
\hline & & & & Negative & Positive & & & & \\
\hline \multirow[t]{4}{*}{ Tumor size (large vs. small) } & Tumor type & & & & & & & & \\
\hline & Digestive system cancer & {$[7,14-16]$} & 530 & 114 vs. 169 & 84 vs. 163 & 1.49 & $1.00-2.22$ & 51.3 & 0.08 \\
\hline & Urinary system cancer & [17] & 66 & 6 vs. 29 & 5 vs. 26 & 1.08 & $0.29-3.95$ & NA & NA \\
\hline & Total & & 596 & 120 vs. 198 & 89 vs. 189 & 1.45 & $0.99-2.12$ & 40.8 & 0.13 \\
\hline \multirow[t]{5}{*}{ T category (T3 + 4 vs. $\mathrm{T} 1+2)$} & Tumor type & & & & & & & & \\
\hline & Digestive system cancer & {$[15,19]$} & 238 & 96 vs. 24 & 95 vs. 23 & 0.98 & $0.46-2.08$ & 25.1 & 0.26 \\
\hline & Urinary system cancer & {$[17]$} & 66 & 22 vs. 13 & 8 vs. 23 & 4.87 & $1.69-14.0$ & NA & NA \\
\hline & Head and neck cancer & {$[18]$} & 190 & 44 vs. 73 & 16 vs. 57 & 2.15 & $1.10-4.19$ & NA & NA \\
\hline & Total & & 494 & 162 vs. 110 & 119 vs. 103 & 1.68 & $0.82-3.43$ & 60.8 & 0.04 \\
\hline \multirow[t]{8}{*}{$\mathrm{N}$ category $\left(\mathrm{N}^{+}\right.$vs. $\left.\mathrm{N}^{-}\right)$} & Tumor type & & & & & & & & \\
\hline & Digestive system cancer & {$[15,19,23]$} & 465 & 164 vs. 119 & 91 vs. 91 & 1.02 & $0.53-1.93$ & 58.5 & 0.05 \\
\hline & Head and neck cancer & {$[20,21]$} & 114 & 19 vs. 36 & 11 vs. 48 & 3.39 & $0.59-19.53$ & 55.3 & 0.14 \\
\hline & $\begin{array}{l}\text { Respiratory system } \\
\text { cancer }\end{array}$ & {$[22]$} & 124 & 44 vs. 59 & 11 vs. 10 & 0.68 & $0.26-1.74$ & NA & NA \\
\hline & Population & & & & & & & & \\
\hline & Asian & {$[15,19-21,23]$} & 579 & 183 vs. 155 & 102 vs. 139 & 1.26 & $0.68-2.33$ & 58.8 & 0.02 \\
\hline & European & {$[22]$} & 124 & 44 vs. 59 & 11 vs. 10 & 0.68 & $0.26-1.74$ & NA & NA \\
\hline & Total & & 703 & 227 vs. 214 & 113 vs. 149 & 1.15 & $0.67-1.68$ & 55.4 & 0.03 \\
\hline \multirow[t]{5}{*}{ M category $\left(\mathrm{M}^{+}\right.$vs. $\left.\mathrm{M}^{-}\right)$} & Tumor type & & & & & & & & \\
\hline & Urinary system tumor & {$[17]$} & 66 & 22 vs. 13 & 8 vs. 23 & 4.87 & $1.69-14.0$ & NA & NA \\
\hline & Head and neck cancer & [18] & 190 & 10 vs. 107 & 4 vs. 69 & 1.61 & $0.49-5.34$ & NA & NA \\
\hline & Digestive system cancer & {$[19,23]$} & 213 & 4 vs. 117 & 4 vs. 88 & 0.72 & $0.09-5.83$ & 54 & 0.14 \\
\hline & Total & & 469 & 36 vs. 237 & 16 vs. 180 & 2.51 & $1.20-5.26$ & 46.2 & 0.10 \\
\hline
\end{tabular}

OR odds ratio, $\mathrm{Cl}$ confidence interval, $N A$ not available

a The data of PDCD4 expression are expressed as the number of cases in the former subgroup versus the number of cases in the latter subgroup, e.g., the number of cases in the large tumor subgroup versus the number of cases in the small tumor subgroup

1.87-9.66) $[20,21]$ and digestive system cancers (OR 2.87, 95\% CI 1.84-4.48) [15, 23, 25-27] (Fig. 3a). No publication bias was observed (Figs. 2b, 3b).

\section{Quantitative analysis of the association between PDCD4 expression and $O S$}

Combined analysis of the 20 studies in 10 papers that addressed OS $[7,15,17,18,24,28-32]$ showed that reduced PDCD4 expression had an unfavorable impact on the OS of patients with solid tumors (HR: 2.24, 95\% CI 1.93-2.60) (Table 3). Significant associations were observed in the univariate model (HR: 2.05 , 95\% CI 1.692.49) and multivariate model (HR: 2.52, 95\% CI 2.013.16) (Fig. 4a). Subgroup analysis of different tumor types (Table 3) showed that reduced PDCD4 expression had an unfavorable impact on the OS of patients with head and neck cancers (HR: 3.24, 95\% CI 1.93-5.45) [18, 24, 29], breast cancers (HR: 1.86, 95\% CI 1.36-2.54) [30], digestive system cancers (HR: 2.12, 95\% CI 1.75-2.56) [7, 15, $28,31,32$ ], and urinary system cancers (HR: $3.16,95 \%$ CI
1.06-9.41) [17]. No evidence of significant publication bias was observed with Begg's test $(P=0.940)$ and Egger's test $(P=0.744)$ (Fig. 4b).

\section{Quantitative analysis of the association between PDCD4 expression and DSS}

In total, 4 studies that addressed DSS were pooled for analysis [24, 28, 33, 34]. The pooled HR showed significant differences in DSS between the high and low PDCD4 expression groups (HR: 3.59, 95\% CI 1.23-10.50) (Fig. 5a). Down-regulation of PDCD4 expression was associated with unsatisfactory DSS in patients with head and neck cancers (HR: 5.05, 95\% CI 1.12-62.50) [24], brain tumors (HR: 15.87, 95\% CI 3.62-71.43) [33], and gynecologic cancers (HR: 3.36, 95\% CI 1.43-7.81) [34]. For digestive system cancers, no association was demonstrated (HR: 1.31, 95\% CI 1.00-1.72) [28]. An association between low PDCD4 expression and short DSS was found in patients from Asia (HR: 5.67, 95\% CI 2.135.12) but not in patients from Europe (HR: 1.31, 95\% 
a Study ID
Clinical stage

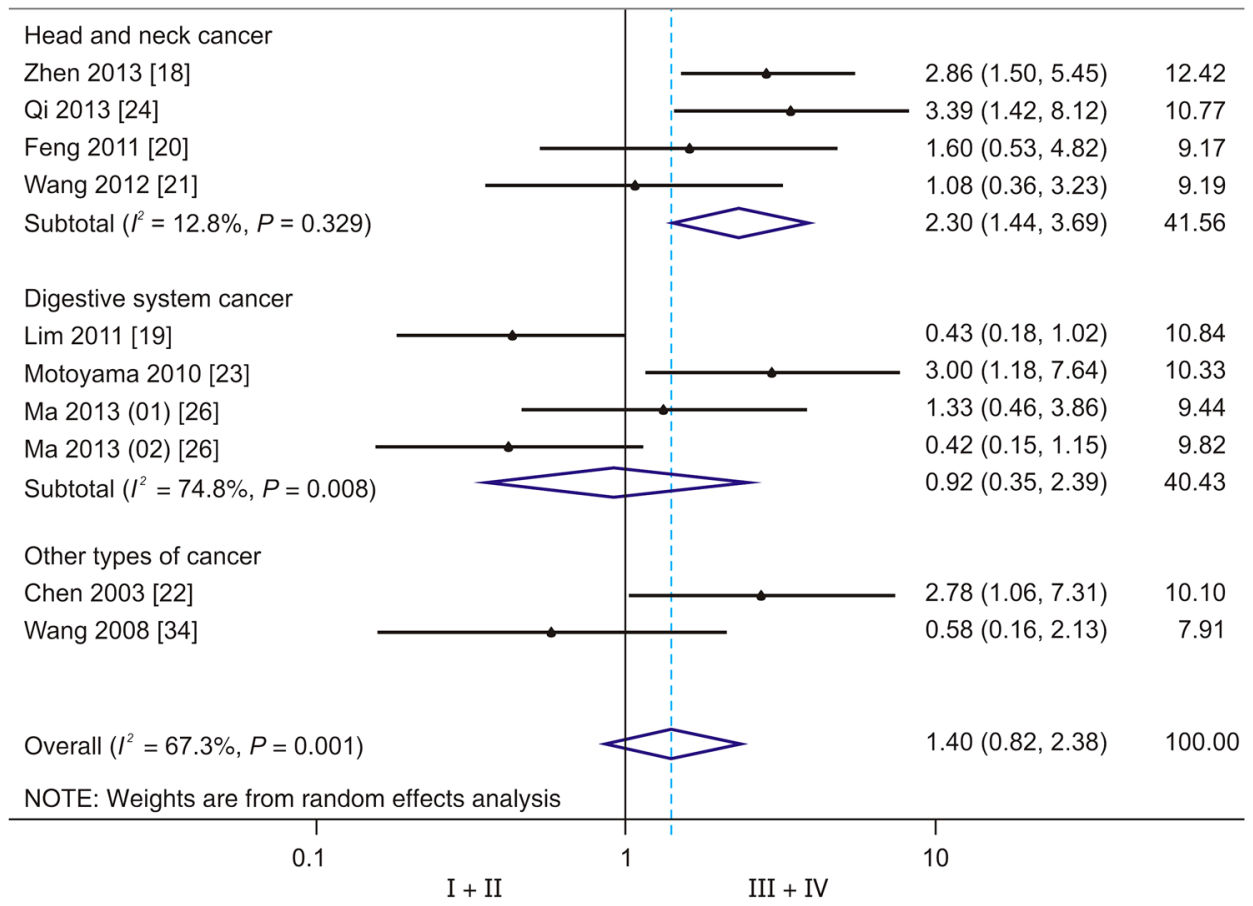

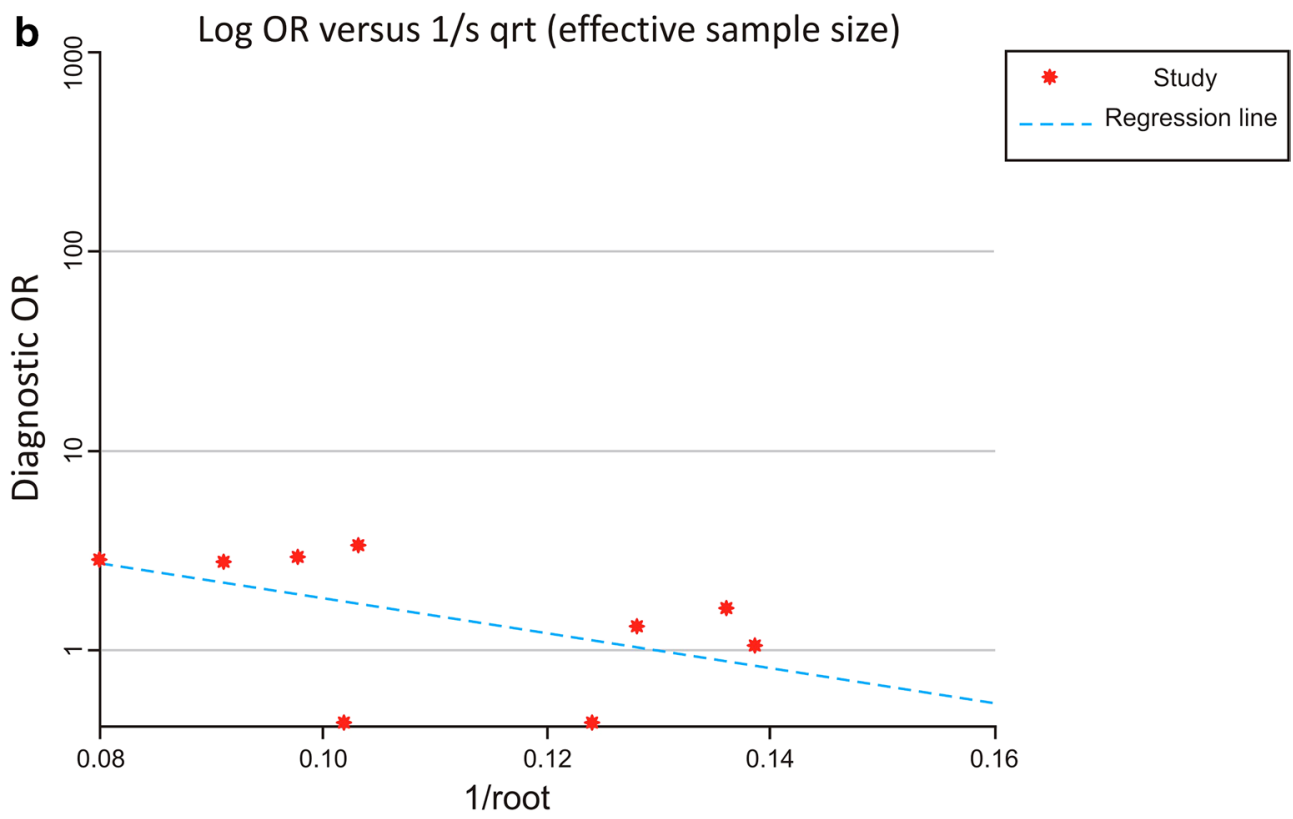

Fig. 2 Forest plots and funnel plots demonstrating the associations between programmed cell death protein 4 (PDCD4) expression and clinical stage of various types of cancer. a Forest plot shows that low PDCD4 expression is significantly associated with advanced stages of head and neck cancers. Two cancer types were reported by Ma et al.: Ma [26] (01) for gastric cancer and Ma [26] (02) for pancreatic cancer. OR odds ratio, Cl confidence interval. $\mathbf{b}$ Funnel plot shows no evidence of publication bias among papers on the association between PDCD4 expression and clinical stage of various types of cancer 
a Study ID
Histological differentiation

Digestive system cancer Nagao 2012 (01) [15]

Nagao 2012 (02) [15]

Motoyama 2010 [23]

Ma 2013 (01) [26]

Ma 2013 (02) [26]

Ma 2013 (03) [26]

Yu 2014 [27]

Kakimoto 2011 (01) [50]

Kakimoto 2011 (02) [50]

Subtotal $\left(I^{2}=59.6 \%, P=0.011\right)$

Urinary system tumor

Li 2012 [17]

Head and neck cancer

Feng 2011 [20]

Wang 2012 [21]

Subtotal $\left(I^{2}=0.0 \%, P=0.780\right)$

Heterogeneity between groups: $P=0.681$

Overall $\left(I^{2}=46.7 \%, P=0.037\right)$
OR $(95 \% \mathrm{Cl})$

Weight

(\%)

\begin{tabular}{lr}
$1.71(0.55,5.35)$ & 10.29 \\
$0.72(0.22,2.39)$ & 9.21 \\
$1.74(0.60,5.07)$ & 11.69 \\
$6.67(2.15,20.63)$ & 10.45 \\
$52.00(5.97,453.13)$ & 2.84 \\
$5.62(1.92,16.49)$ & 11.51 \\
$7.71(1.28,46.36)$ & 4.14 \\
$2.25(0.31,16.41)$ & 3.38 \\
$0.95(0.14,6.28)$ & 3.75 \\
\hline $.87(1.84,4.48)$ & 67.27
\end{tabular}

$2.87(1.84,4.48) \quad 67.27$

$2.67(0.96,7.37) \quad 12.89$

$3.77(1.16,12.27) \quad 9.57$

$4.76(1.52,14.88) \quad 10.26$

$4.25(1.87,9.66) \quad 19.84$

$3.07(2.13,4.43) \quad 100.00$

\begin{tabular}{c|c|c}
0.1 & 1 \\
Well differentiation & 1 & 10 \\
\multicolumn{2}{c}{ Moderate/poor differentiation }
\end{tabular}

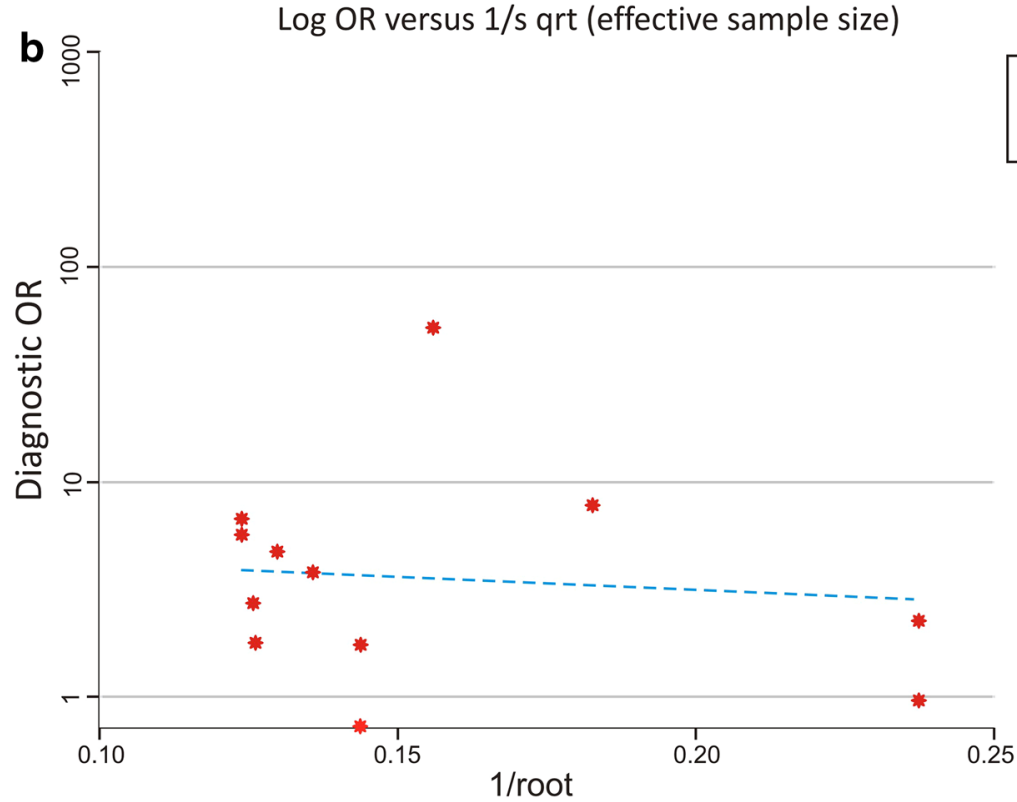

Fig. 3 Forest plots and funnel plots demonstrating the associations between PDCD4 expression and histological differentiation of various types of cancer. a Forest plot shows that low PDCD4 expression is significantly associated with moderate/poor differentiation of digestive system cancers and head and neck cancers. Two sites of PDCD4 expression were reported by Kakimoto et al.: Kakimoto [50] (01) for PDCD4 expression in nucleus and Kakimoto [50] (02) for PDCD4 expression in cytoplasm of gastric cancer cells. Two sites of PDCD4 expression were reported by Nagao et al.: Nagao [15] (01) for PDCD4 expression in nucleus and Nagao [15] (02) for PDCD4 expression in cytoplasm of pancreatic cancer cells. Three cancer types were reported by Ma et al.: Ma [26] (01) for gastric cancer, Ma [26] (02) for pancreatic cancer, and Ma [26] (03) for colorectal cancer. OR odds ratio, $\mathrm{Cl}$ confidence interval. b Funnel plot shows no evidence of publication bias among papers on the association between PDCD4 expression and histological differentiation of various types of cancer 


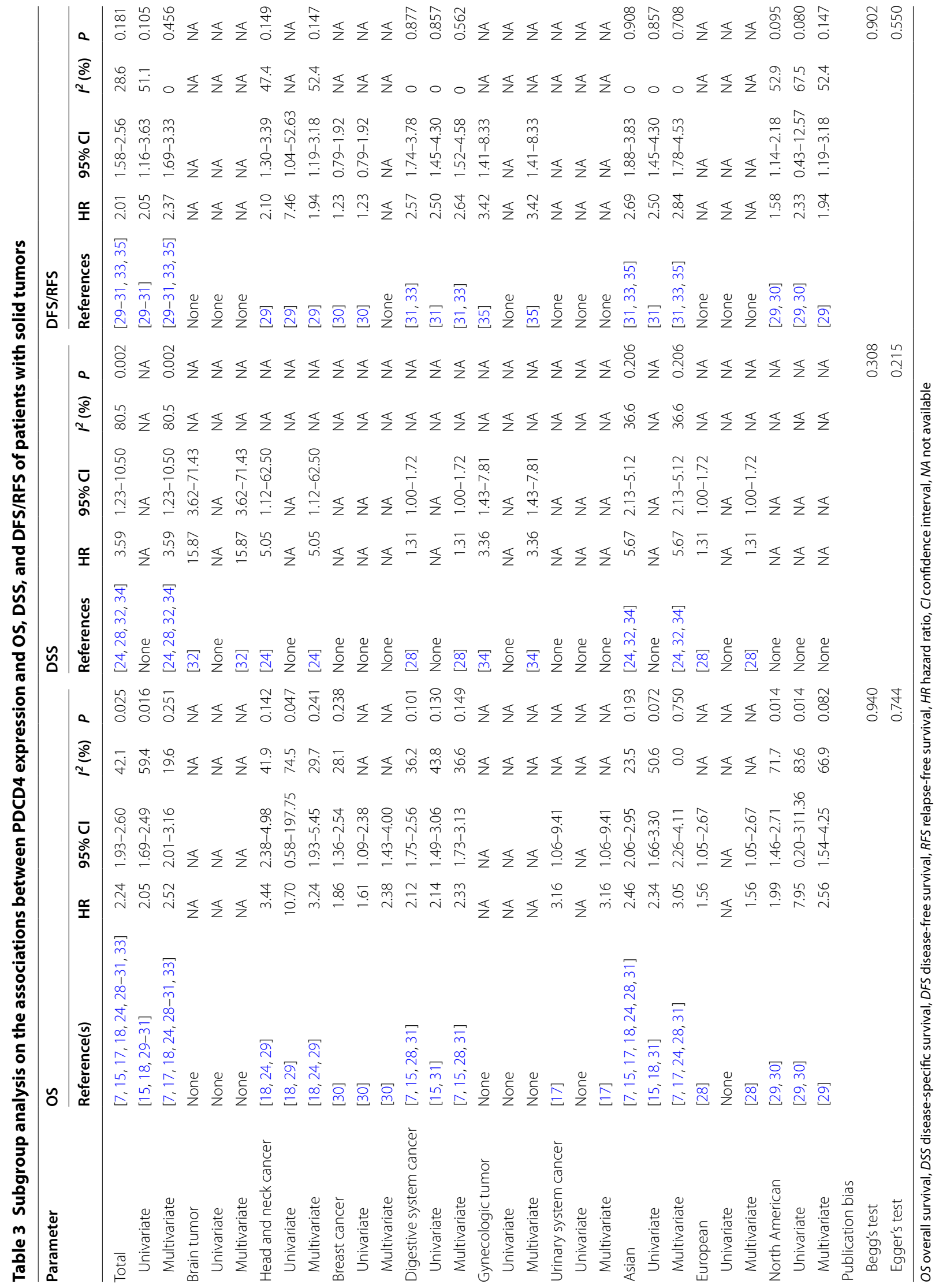


a $\begin{array}{llll}\text { Study } & \text { OS } & \text { HR }(95 \% \mathrm{Cl}) & \text { Weigh } \\ \text { ID }\end{array}$

Multivariate analysis

Guo 2013 (01) [7]

Guo $2013(02)[7]$

Li 2012 [17]

Zhen 2013 (01) [18]

Qi 2013 [24]

Mudduluru 2007 [28]

Reis 2010 (01) [29]

Meric-Bernstam 2012 (01) [30]

Horiuchi 2012 (01) [31]

Horiuchi 2012 (02) [31]

Horiuchi 2012 (03) [31]

Dou 2014 [32]

Subtotal $\left(I^{2}=19.6 \%, P=0.251\right)$

Univariate analysis

Nagao 2012 (01) [15]

Nagao 2012 (02) [15]

Zhen 2013 (02) [18]

Reis 2010 (03) [29]

Meric-Bernstam 2012 (02) [30]

Horiuchi 2012 (04) [31]

Horiuchi 2012 (05) [31]

Horiuchi 2012 (06) [31]

Subtotal $\left(I^{2}=59.4 \%, P=0.016\right)$

Heterogeneity between groups: $P=0.174$

Overall $\left(I^{2}=12.8 \%, P=0.329\right)$

$5.94(1.53,12.34)$
$4.86(1.33,9.34)$

$3.16(1.06,9.41) \quad 1.84$

$2.92(1.69,5.03) \quad 7.40$

$5.38(1.07,76.92) \quad 0.48$

$1.56(1.05,2.67) \quad 10.00$

$45.45(1.40,1000.00) \quad 0.20$

$2.38(1.43,4.00) \quad 8.24$

$3.42(1.22,9.30) \quad 2.11$

$3.25(1.30,9.22) \quad 2.27$

$1.96(1.01,3.78) \quad 5.04$

$1.82(0.25,4.34) \quad 1.07$

$2.52(2.01,3.16) \quad 42.95$

$2.27(1.45,3.55) \quad 10.95$

$1.35(0.90,2.02) \quad 13.12$

$3.33(1.96,5.68) \quad 7.69$

$71.43(2.56,1000.00) \quad 0.25$

$1.61(1.09,2.38) \quad 14.21$

$2.83(1.15,7.13) \quad 2.62$

$4.25(1.79,11.67) \quad 2.49$

$2.25(1.22,4.18) \quad 5.74$

$2.05(1.69,2.49) \quad 57.05$

$2.24(1.93,2.60) \quad 100.00$

\section{b Begg's funnel plot with pseudo $95 \%$ confidence limits}

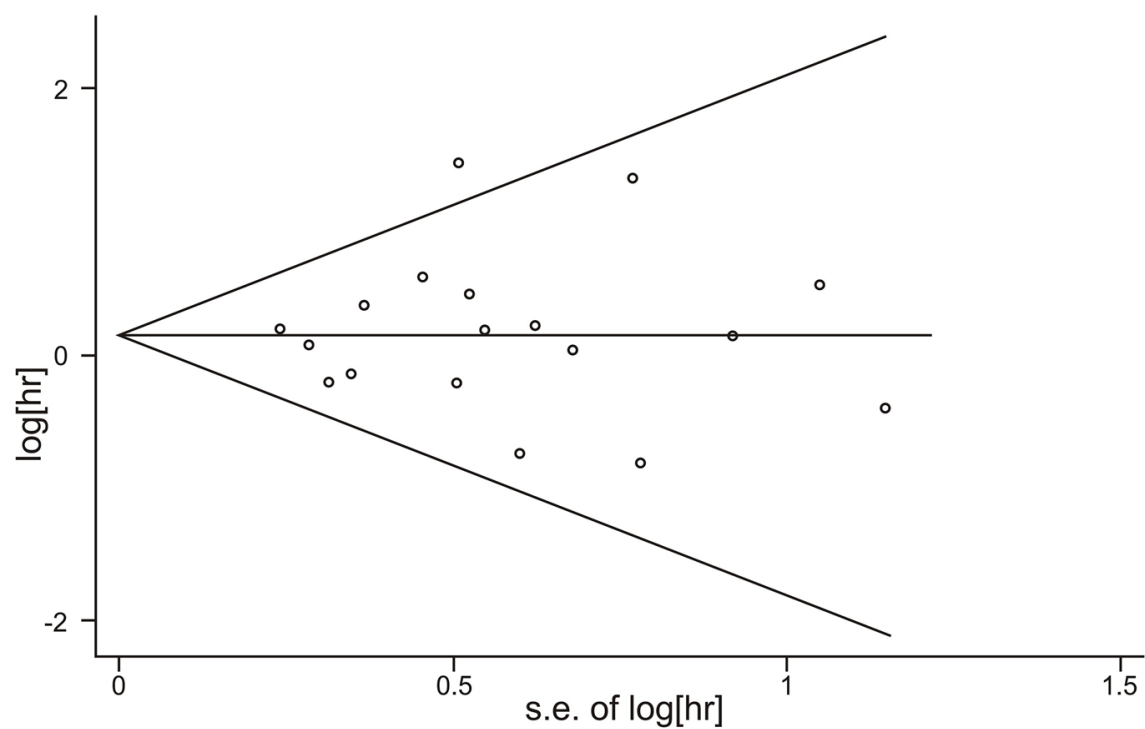

Fig. 4 Forest plots and funnel plots demonstrating the associations between PDCD4 expression and overall survival (OS) of patients with solid tumors. a Forest plot shows that low PDCD4 expression level is significantly associated with a low OS rate. In total, 20 studies from 10 papers were included. Two T subcategories of gastric cancer were reported by Guo et al.: Guo [7] (01) for pT2a gastric cancer and Guo [7] (02) for pT2b gastric cancer. Two sites of PDCD4 expression were reported by Nagao et al.: Nagao [15] (01) for PDCD4 expression in nucleus and Nagao [15] (02) for PDCD4 expression in cytoplasm of pancreatic cancer cells. Different Duke's stages were reported by Horiuchi et al.: Horiuchi [31] (01) for Duke's stage B, Horiuchi [31] (02) for Duke's stage C, and Horiuchi [31] (03) for Duke's stage D colorectal cancer in multivariate analysis; Horiuchi [31] (04) for Duke's stage B, Horiuchi [31] (05) for Duke's stage C, and Horiuchi [31] (05) for Duke's stage D colorectal cancer in univariate analysis. A fixed effects model was used to calculate the pooled hazard ratio (HR) for OS. Significant associations are observed in univariate model and in multivariate model. b Funnel plot shows no evidence of publication bias among papers on the association between PDCD4 expression and overall survival rate of various types of cancer. s.e. standard error. The $P$ value is 0.940 in Begg's test and is 0.744 in Egger's test 

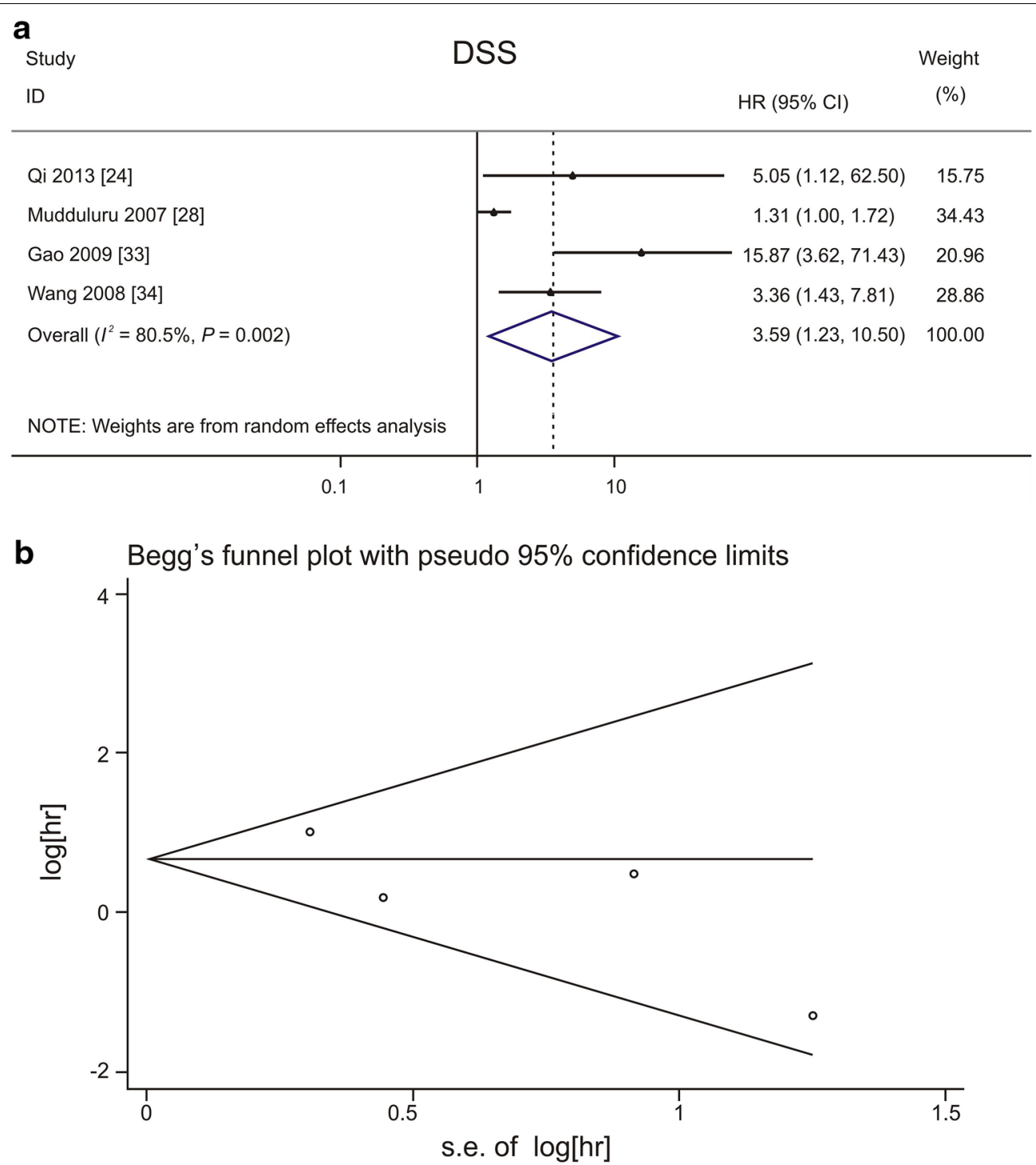

Fig. 5 Forest plots and funnel plots demonstrating the associations between PDCD4 expression and disease-specific survival (DSS) of patients with solid tumors. a Forest plot shows that low PDCD4 expression level is significantly associated with a low DSS rate. A random effects model was used to calculate the pooled HR for DSS. b Funnel plot shows no evidence of publication bias among papers on the association between PDCD4 expression and disease-specific survival rate of various types of cancer. The $P$ value is 0.308 in Begg's test and is 0.215 in Egger's test

CI 1.00-1.72) (Table 3). The Begg's test $(P=0.308)$ and Egger's test $(P=0.215)$ showed no significant publication bias (Fig. 5b).

\section{Quantitative analysis of the association between PDCD4 expression and DFS/RFS}

The pooled HR for DFS/RFS showed a significant association with PDCD4 down-regulation (HR: 2.01, 95\% CI 1.58-2.56) (Fig. 6a) [29-32, 35]. Low PDCD4 expression was associated with short DFS/RFS of patients with head and neck cancers (HR: 2.10, 95\% CI 1.30-3.39) [29], digestive system cancers (HR: 2.57, 95\% CI 1.74-3.78)
[31, 32], and gynecologic cancers (HR: 3.42, 95\% CI 1.418.33) [35]; for breast cancer patients, no association was observed (HR: 1.23, 95\% CI 0.79-1.92) [30] (Table 3). The Begg's test $(P=0.902)$ and Egger's test $(P=0.550)$ showed no significant publication bias (Fig. 6b).

\section{Discussion}

In this meta-analysis, we examined the association between PDCD4 expression and the clinicopathologic parameters of cancers from different anatomical sites, including the brain, head and neck, breast, and digestive, gynecologic, and urinary systems. Our results indicated 


\section{a}

DFS/RFS

ID

$\operatorname{HR}(95 \% \mathrm{Cl})$

Weight

\begin{tabular}{|c|c|c|}
\hline & & \\
\hline Multivariate analysis & & \\
\hline Reis 2010 (01) [29] & & $8.33(1.08,62.50) \quad 1.39$ \\
\hline Reis 2010 (02) [29] & $\longrightarrow$ & $1.77(1.07,2.95) \quad 22.22$ \\
\hline Horiuchi 2012 (01) [31] & & $3.34(1.28,10.34) \quad 5.28$ \\
\hline Horiuchi 2012 (02) [31] & & $2.10(1.06,4.37) \quad 11.39$ \\
\hline Dou 2014 [32] & & $4.80(0.42,9.92) \quad 2.30$ \\
\hline Wei 2009 [35] & & $3.42(1.41,8.33) \quad 7.25$ \\
\hline Subtotal $\left(I^{2}=0.0 \%, P=0.456\right)$ & & $2.37(1.69,3.33) \quad 49.83$ \\
\hline Univariate analysis & & \\
\hline Reis 2010 (03) [29] & & $7.46(1.04,52.63) \quad 1.49$ \\
\hline Meric-Bernstam 2012 (02) [30] & - & $1.23(0.79,1.92) \quad 29.32$ \\
\hline Horiuchi 2012 (04) [31] & - & $2.67(1.14,6.94) \quad 7.02$ \\
\hline Horiuchi 2012 (05) [31] & - & $2.40(1.24,4.86) \quad 12.35$ \\
\hline Subtotal $\left(I^{2}=51.1 \%, P=0.105\right)$ & $\infty$ & $1.71(1.22,2.40) \quad 50.17$ \\
\hline Heterogeneity between groups: $P=0.181$ & & \\
\hline Overall $\left(I^{2}=28.6 \%, P=0.181\right)$ & 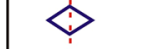 & $2.01(1.58,2.56) 100.00$ \\
\hline
\end{tabular}

b Begg's funnel plot with pseudo $95 \%$ confidence limits

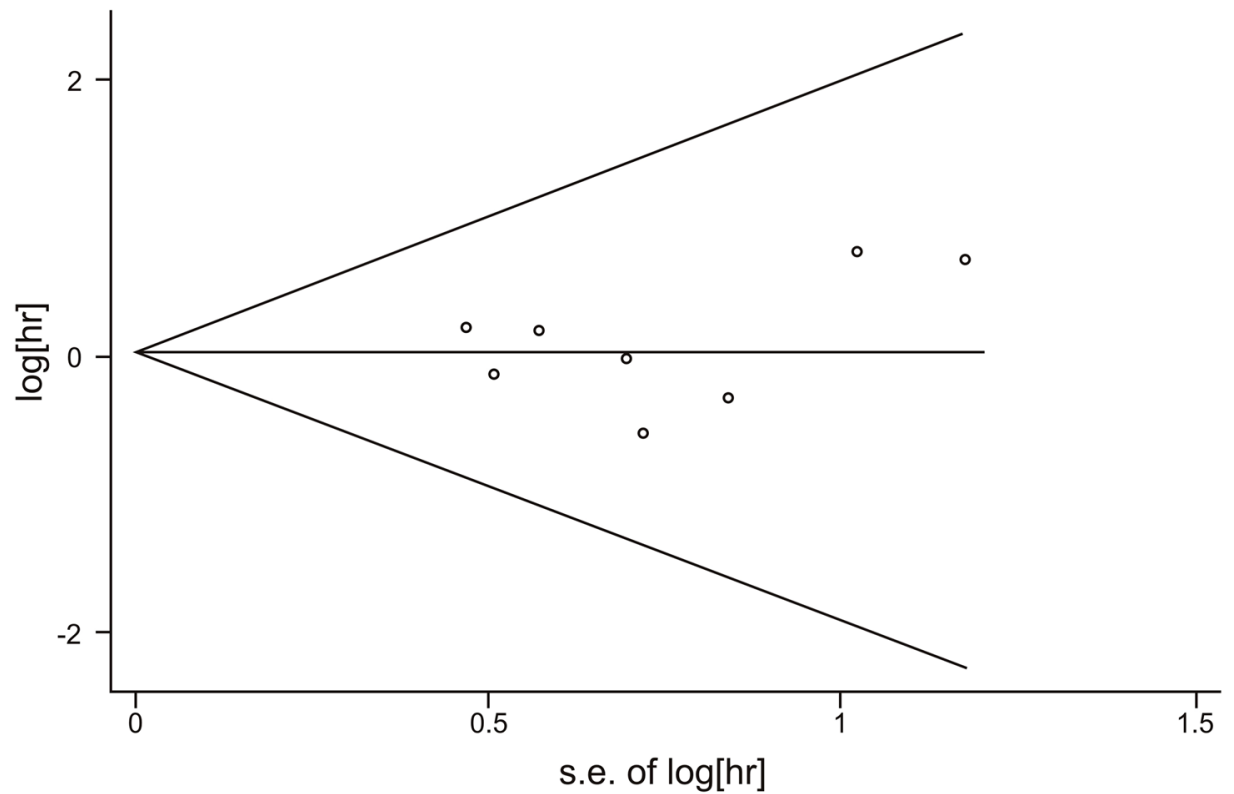

Fig. 6 Forest plots and funnel plots demonstrating the associations between PDCD4 expression and disease-free survival (DFS)/relapse-free survival (RFS) of patients with solid tumors. a Forest plot shows that low PDCD4 expression level is significantly associated with a low DFS/RFS rate. In total, 10 studies in 5 papers were included. A fixed effects model was used to calculate the pooled HR for DFS/RFS. Significant associations are observed in univariate model and in multivariate model. Different Duke's stages were reported by Horiuchi et al.: Horiuchi [31] (01) for Duke's stage B and Horiuchi [31] (02) for Duke's stage C colorectal cancer in multivariate analysis; Horiuchi [31] (04) for Duke's stage B and Horiuchi [31] (05) for Duke's stage C colorectal cancer in univariate analysis. b Funnel plot shows no evidence of publication bias among papers on the association between PDCD4 expression and disease-free survival rate of various types of cancer. The $P$ value is 0.902 in Begg's test and is 0.550 in Egger's test 
a strong negative association of PDCD4 expression with tumor size and differentiation status of solid tumors. In a stratified analysis, reduced PDCD4 expression level was associated with late $\mathrm{T}$ subcategories in head and neck tumors and urinary system cancers as well as distant metastasis of urinary system cancers. Furthermore, low PDCD4 expression was associated with advanced stage head and neck cancers and respiratory system cancers.

Epithelial differentiation was a determining factor in the prognoses of head and neck cancers. Poorly differentiated cancers were highly proliferative compared with their highly differentiated counterparts. In addition, differentiation status was important in maintaining a tumorigenic and treatment-resistant cancer stem cell subpopulation in head and neck cancers [36]. Hence, cancer treatment with differentiation inducers (such as retinoic acid) could inhibit cancer cell proliferation and is known as differentiation cancer therapy [37, 38]. In head and neck cancers, it had been demonstrated that valproic acid or all-trans retinoic acid could inhibit the growth of head and neck squamous cell carcinomas by inducing terminal differentiation [39]. Furthermore, differentiation therapy could help in suppressing and eradicating the cancer stem cell population in head and neck squamous cell carcinomas [36, 40]. The association between PDCD4 expression and cancer cell differentiation was clearly demonstrated in peripheral blood cancers. PDCD4 expression was induced in NB4 and HL-60 acute myelocytic leukemia (AML) cell lines, primary human promyelocytic leukemia (AML-M3) cells, and $\mathrm{CD}_{4}{ }^{+}$hematopoietic progenitor cells in the presence of all-trans retinoic acid. Differentiation induction could be prevented if PDCD4 was silenced using small interfering RNA (siRNA) [41]. In solid tumors, PDCD4 expression was inhibited by the phosphatidylinositol 3-kinase (PI3K)/protein kinase B (PKB/AKT)/mammalian target of rapamycin (mTOR) pathway. During adipogenic differentiation of adipose tissue-derived mesenchymal stem cells, PDCD4 expression was reduced and AKT phosphorylation was increased in a time-dependent manner [42]. Because of the association between PDCD4 and cancer differentiation, PDCD4 restoration could be a novel approach for differentiation cancer therapy, resulting in effective suppression of solid tumor development and further improving the prognosis [43].

In urinary system cancer, PDCD4 suppression was associated with the metastatic status of the patients [17]. PDCD4-knockout mice developed spontaneous lymphomas with systematic dissemination and frequent liver/renal metastasis [44]. Preclinical studies have indicated that PDCD4 could control key genes involved in cancer migration and metastasis $[25,45,46]$. The expression of urokinase plasminogen activator surface receptor (u-PAR), which mediates plasmin-mediated extracellular matrix degradation, was shown to be controlled by PDCD4 [45]. In PDCD4-knockdown cancer cells, epithelial cadherin 1 (E-cadherin) promoter activity was inhibited. In contrast, in colorectal cancer cells overexpressing PDCD4, E-cadherin protein level was increased accordingly [25]. In ACHN and 786-O renal cancer cells, PDCD4 regulated AKT phosphorylation, leading to the migration or invasion of cancer cells via the up-regulation of the mammalian target of rapamycin complex 1 (mTORC1) [46]. Metastasis of cancer cells is a main cause of death in laryngeal carcinoma patients. Moreover, molecular factors involved in metastasis, especially in the epithelial-mesenchymal transition (EMT), could be a possible mechanism of cancer cell resistance. Because low PDCD4 expression was significantly associated with metastasis in urinary system cancers, PDCD4 could be a novel target for improving the prognosis of this malignancy.

Several limitations were observed in this meta-analysis. A small sample size was observed in one cancer group. Moreover, multiple cut-off criteria, discrepancies among diverse tumor properties, and the therapy received also affected the results. In most of the studies included in prognostic assessment, all clinical stages were represented in the respective cancer cases. However, the study reported by Dou et al. [32], only focused on advanced stage rectal cancer, and the low PDCD4 expression within these patients was not significantly associated with the 5-year OS or DFS indicated by the 95\% CI overlapping 1. Furthermore, the subcellular localization of the PDCD4 protein affects cancer behavior. During tumor progression, PDCD4 protein translocation from the nucleus to the cytoplasm was observed in cancer cells [47, 48]. Accumulation of cytoplasmic PDCD4 protein is reported in both normal and cancer cell lines [49]. Almost all of the studies included in our meta-analysis measured the total PDCD4 protein level in the tissue samples rather than the separate nuclear or cytoplasmic PDCD4 protein level. In the study conducted by Nagao et al. [15], both nuclear and cytoplasmic PDCD4 protein pools were examined in pancreatic cancer patients. Different ORs and 95\% CIs were obtained for the assessment of clinical stage and OS. A similar situation was observed in the study by Kakimoto et al. [50] that examined the association between PDCD4 expression and histological differentiation. These findings suggest that the prognostic value of PDCD4 in human malignancies should be studied by further stratified analysis, including the determination of precise cellular localization of PDCD4. 


\section{Conclusions}

Our results demonstrated that reduced expression of PDCD4 in solid tumors is an unfavorable prognostic indicator. We noticed that the sample size for a particular cancer group was not large enough to define the prognostic value of PDCD4, and not having nucleus-specific PDCD4 protein measurements could also restrict the precise evaluation. Future studies on a larger scale are warranted to address the association of PDCD4 with the unique clinical features presented by different cancers.

\section{Authors' contributions}

This meta-analysis on prognostic significance of PDCD4 in solid tumors was designed by TSW, WIW, and JZHL. JZHL and WG performed the independent systemic literature review and data summary, respectively. TSW, WKH, and JZHL were responsible for the analysis of pooled data. Finally, the manuscript was written and modified by JZHL, WG, TSW, WBL, and JYC. All authors read and approved the final manuscript.

\section{Author details}

'Department of Surgery, The University of Hong Kong, Queen Mary Hospital, Hong Kong, Hong Kong, SAR, P. R. China. ${ }^{2}$ Department of Otolaryngology, The First Affiliated Hospital of Sun Yat-sen University, Guangzhou, Guangdong 510080, P. R. China.

\section{Competing interests}

The authors declare that they have no competing interests.

Received: 25 September 2015 Accepted: 15 April 2016

Published online: 16 November 2016

\section{References}

1. Lankat-Buttgereit B, Goke R. The tumour suppressor Pdcd4: recent advances in the elucidation of function and regulation. Biol Cell. 2009;101(6):309-17. doi:10.1042/bc20080191.

2. Cmarik JL, Min H, Hegamyer G, Zhan S, Kulesz-Martin M, Yoshinaga $\mathrm{H}$, et al. Differentially expressed protein Pdcd4 inhibits tumor promoter-induced neoplastic transformation. Proc Natl Acad Sci USA. 1999;96(24):14037-42.

3. Yang HS, Jansen AP, Nair R, Shibahara K, Verma AK, Cmarik JL, et al. A novel transformation suppressor, Pdcd4, inhibits AP-1 transactivation but not NF-kappaB or ODC transactivation. Oncogene. 2001;20(6):669-76. doi:10.1038/sj.onc.1204137.

4. Yang HS, Jansen AP, Komar AA, Zheng X, Merrick WC, Costes S, et al. The transformation suppressor Pdcd4 is a novel eukaryotic translation initiation factor $4 \mathrm{~A}$ binding protein that inhibits translation. Mol Cell Biol. 2003;23(1):26-37.

5. Rogers GW Jr, Richter NJ, Merrick WC. Biochemical and kinetic characterization of the RNA helicase activity of eukaryotic initiation factor 4A. J Biol Chem. 1999;274(18):12236-44.

6. Hwang SK, Baker AR, Young MR, Colburn NH. Tumor suppressor PDCD4 inhibits NF-kappaB-dependent transcription in human glioblastoma cells by direct interaction with p65. Carcinogenesis. 2014;35(7):1469-80. doi:10.1093/carcin/bgu008.

7. Guo PT, Yang D, Sun Z, Xu HM. PDCD4 functions as a suppressor for pT2a and pT2b stage gastric cancer. Oncol Rep. 2013;29(3):1007-12. doi:10.3892/or.2013.2232.

8. Fischer N, Goke F, Splittstosser V, Lankat-Buttgereit B, Muller SC, Ellinger J. Expression of programmed cell death protein 4 (PDCD4) and miR-21 in urothelial carcinoma. Biochem Biophys Res Commun. 2012;417(1):29-34. doi:10.1016/j.bbrc.2011.11.035.

9. Yang Y, Meng H, Peng Q, Yang X, Gan R, Zhao L, et al. Downregulation of microRNA-21 expression restrains non-small cell lung cancer cell proliferation and migration through upregulation of programmed cell death 4. Cancer Gene Ther. 2015;22(1):23-9. doi:10.1038/cgt.2014.66.

10. Kalinichenko SV, Kopantzev EP, Korobko EV, Palgova IV, Zavalishina LE, Bateva MV, et al. Pdcd4 protein and mRNA level alterations do not correlate in human lung tumors. Lung Cancer. 2008;62(2):173-80. doi:10.1016/j. lungcan.2008.03.022.

11. Lankat-Buttgereit B, Muller S, Schmidt H, Parhofer KG, Gress TM, Goke $\mathrm{R}$. Knockdown of $\mathrm{Pdcd} 4$ results in induction of proprotein convertase $1 / 3$ and potent secretion of chromogranin A and secretogranin II in a neuroendocrine cell line. Bio Cell. 2008;100(12):703-15. doi:10.1042/ bc20080052.

12. Stroup DF, Berlin JA, Morton SC, Olkin I, Williamson GD, Rennie D, et al. Meta-analysis of observational studies in epidemiology: a proposal for reporting. Meta-analysis Of Observational Studies in Epidemiology (MOOSE) group. JAMA. 2000;283(15):2008-12.

13. Begg CB, Mazumdar M. Operating characteristics of a rank correlation test for publication bias. Biometrics. 1994;50(4):1088-101.

14. Ding L, Zhang $X$, Zhao M, Qu Z, Huang S, Dong M, et al. An essential role of PDCD4 in progression and malignant proliferation of gastrointestinal stromal tumors. Med Oncol. 2012;29(3):1758-64. doi:10.1007/ s12032-011-0042-6.

15. Nagao Y, Hisaoka M, Matsuyama A, Kanemitsu S, Hamada T, Fukuyama T, et al. Association of microRNA-21 expression with its targets, PDCD4 and TIMP3, in pancreatic ductal adenocarcinoma. Mod Pathol. 2012;25(1):112-21. doi:10.1038/modpathol.2011.142.

16. Cao Z, Yoon JH, Nam SW, Lee JY, Park WS. PDCD4 expression inversely correlated with miR-21 levels in gastric cancers. J Cancer Res Clin Oncol. 2012;138(4):611-9. doi:10.1007/s00432-011-1140-8.

17. Li X, Xin S, Yang D, Li X, He Z, Che $X$, et al. Down-regulation of PDCD4 expression is an independent predictor of poor prognosis in human renal cell carcinoma patients. J Cancer Res Clin Oncol. 2012;138(3):529-35. doi:10.1007/s00432-011-1121-y.

18. Zhen Y, Liu Z, Yang H, Yu X, Wu Q, Hua S, et al. Tumor suppressor PDCD4 modulates miR-184-mediated direct suppression of C-MYC and BCL2 blocking cell growth and survival in nasopharyngeal carcinoma. Cell Death Dis. 2013;4:e872. doi:10.1038/cddis.2013.376.

19. Lim SC, Hong R. Programmed cell death 4 (Pdcd4) expression in colorectal adenocarcinoma: association with clinical stage. Oncol Lett. 2011;2(6):1053-7. doi:10.3892/ol.2011.365.

20. Feng G, Li P, You H, Liu W, Zhang X, Xu X, et al. The expression and clinical pathological significance of PDCD in laryngocarcinoma. Lin chuang er bi yan hou tou jing wai ke za zhi. 2011;25(1):16-9.

21. Wang J, Zhang Y. Expression of programmed cell death 4 and its correlation with proliferation and apoptosis in laryngeal squamous cell carcinoma. Lin chuang er bi yan hou tou jing wai ke za zhi. 2012;26(6):266-9.

22. Chen Y, Knosel T, Kristiansen G, Pietas A, Garber ME, Matsuhashi S, et al. Loss of PDCD4 expression in human lung cancer correlates with tumour progression and prognosis. J Pathol. 2003;200(5):640-6. doi:10.1002/ path.1378.

23. Motoyama K, Inoue H, Mimori K, Tanaka F, Kojima K, Uetake H, et al. Clinicopathological and prognostic significance of PDCD4 and microRNA-21 in human gastric cancer. Int J Oncol. 2010;36(5):1089-95.

24. Qi C, Shao Y, Li N, Zhang C, Zhao M, Gao F. Prognostic significance of PDCD4 expression in human salivary adenoid cystic carcinoma. Med Oncol. 2013:30(1):491. doi:10.1007/s12032-013-0491-1.

25. Wang Q, Sun ZX, Allgayer H, Yang HS. Downregulation of E-cadherin is an essential event in activating beta-catenin/Tcf-dependent transcription and expression of its target genes in Pdcd4 knockdown cells. Oncogene. 2010;29(1):128-38. doi:10.1038/onc.2009.302.

26. Ma G, Zhang H, Dong M, Zheng X, Ozaki I, Matsuhashi S, et al. Downregulation of programmed cell death 4 (PDCD4) in tumorigenesis and progression of human digestive tract cancers. Tumour Biol. 2013;34(6):387985. doi:10.1007/s13277-013-0975-9.

27. Yu H, Zeng J, Liang $X$, Wang W, Zhou Y, Sun Y, et al. Helicobacter pylori promotes epithelial-mesenchymal transition in gastric cancer by downregulating programmed cell death protein 4 (PDCD4). Plos ONE. 2014;9(8):e105306. doi:10.1371/journal.pone.0105306.

28. Mudduluru G, Medved F, Grobholz R, Jost C, Gruber A, Leupold JH, et al. Loss of programmed cell death 4 expression marks adenoma-carcinoma 
transition, correlates inversely with phosphorylated protein kinase B, and is an independent prognostic factor in resected colorectal cancer. Cancer. 2007;110(8):1697-707. doi:10.1002/cncr.22983.

29. Reis PP, Tomenson M, Cervigne NK, Machado J, Jurisica I, Pintilie M, et al. Programmed cell death 4 loss increases tumor cell invasion and is regulated by miR-21 in oral squamous cell carcinoma. Mol Cancer. 2010;9:238. doi:10.1186/1476-4598-9-238.

30. Meric-Bernstam F, Chen H, Akcakanat A, Do KA, Lluch A, Hennessy BT, et al. Aberrations in translational regulation are associated with poor prognosis in hormone receptor-positive breast cancer. Breast Cancer Res. 2012;14(5):R138. doi:10.1186/bcr3343.

31. Horiuchi A, linuma $H$, Akahane T, Shimada R, Watanabe T. Prognostic significance of PDCD4 expression and association with microRNA-21 in each Dukes'stage of colorectal cancer patients. Oncol Rep. 2012;27(5):1384-92. doi:10.3892/or.2012.1648

32. Dou X, Wang RB, Meng XJ, Yan HJ, Jiang SM, Zhu KL, et al. PDCD4 as a predictor of sensitivity to neoadjuvant chemoradiotherapy in locally advanced rectal cancer patients. Asian Pac J Cancer Prev. 2014;15(2):825-30.

33. Gao F, Wang X, Zhu F, Wang Q, Zhang X, Guo C, et al. PDCD4 gene silencing in gliomas is associated with $5^{\prime} \mathrm{CpG}$ island methylation and unfavourable prognosis. J Cell Mol Med. 2009;13(10):4257-67. doi:10.1111/j.1582-4934.2008.00497.x.

34. Wang X, Wei Z, Gao F, Zhang X, Zhou C, Zhu F, et al. Expression and prognostic significance of PDCD4 in human epithelial ovarian carcinoma. Anticancer Res. 2008;28(5b):2991-6.

35. Wei NA, Liu SS, Leung TH, Tam KF, Liao XY, Cheung AN, et al. Loss of programmed cell death $4(\mathrm{Pdcd} 4)$ associates with the progression of ovarian cancer. Mol Cancer. 2009;8:70. doi:10.1186/1476-4598-8-70.

36. Lim YC, Kang HJ, Kim YS, Choi EC. All-trans-retinoic acid inhibits growth of head and neck cancer stem cells by suppression of Wnt/beta-catenin pathway. Eur J Cancer. 2012;48(17):3310-8. doi:10.1016/j.ejca.2012.04.013.

37. Leszczyniecka M, Roberts T, Dent P, Grant S, Fisher PB. Differentiation therapy of human cancer: basic science and clinical applications. Pharmacol Ther. 2001;90(2-3):105-56.

38. Hansen LA, Sigman CC, Andreola F, Ross SA, Kelloff GJ, De Luca LM. Retinoids in chemoprevention and differentiation therapy. Carcinogenesis. 2000;21(7):1271-9.

39. Gan CP, Hamid S, Hor SY, Zain RB, Ismail SM, Wan Mustafa WM, et al. Valproic acid: growth inhibition of head and neck cancer by induction of terminal differentiation and senescence. Head Neck. 2012;34(3):344-53. doi:10.1002/hed.21734.
40. Fatima F, Nawaz M. Stem cell-derived exosomes: roles in stromal remodeling, tumor progression, and cancer immunotherapy. Chin J Cancer. 2015;34(3):46. doi:10.1186/s40880-015-0051-5.

41. Ozpolat B, Akar U, Steiner M, Zorrilla-Calancha I, Tirado-Gomez M, Colburn N, et al. Programmed cell death-4 tumor suppressor protein contributes to retinoic acid-induced terminal granulocytic differentiation of human myeloid leukemia cells. Mol Cancer Res. 2007;5(1):95-108. doi:10.1158/1541-7786.mcr-06-0125.

42. Lo Furno D, Graziano AC, Caggia S, Perrotta RE, Tarico MS, Giuffrida R, et al. Decrease of apoptosis markers during adipogenic differentiation of mesenchymal stem cells from human adipose tissue. Apoptosis. 2013;18(5):578-88. doi:10.1007/s10495-013-0830-x.

43. Yan M, Liu Q. Differentiation therapy: a promising strategy for cancer treatment. Chin J Cancer. 2016;35(1):3. doi:10.1186/s40880-015-0059-X.

44. Hilliard A, Hilliard B, Zheng SJ, Sun H, Miwa T, Song W, et al. Translational regulation of autoimmune inflammation and lymphoma genesis by programmed cell death 4. J Immunol. 2006;177(11):8095-102.

45. Leupold JH, Yang HS, Colburn NH, Asangani I, Post S, Allgayer H. Tumor suppressor Pdcd4 inhibits invasion/intravasation and regulates urokinase receptor (u-PAR) gene expression via Sp-transcription factors. Oncogene. 2007;26(31):4550-62. doi:10.1038/sj.onc.1210234.

46. Bera A, Das F, Ghosh-Choudhury N, Kasinath BS, Abboud HE, Choudhury GG. microRNA-21-induced dissociation of PDCD4 from rictor contributes to Akt-IKKbeta-mTORC1 axis to regulate renal cancer cell invasion. Exp Cell Res. 2014;328(1):99-117. doi:10.1016/j.yexcr.2014.06.022.

47. Bohm M, Sawicka K, Siebrasse JP, Brehmer-Fastnacht A, Peters R, Klempnauer $\mathrm{KH}$. The transformation suppressor protein $\mathrm{Pdcd} 4$ shuttles between nucleus and cytoplasm and binds RNA. Oncogene. 2003;22(31):4905-10. doi:10.1038/sj.onc.1206710.

48. Goke R, Barth P, Schmidt A, Samans B, Lankat-Buttgereit B. Programmed cell death protein 4 suppresses CDK1/cdc2 via induction of p21 (Waf1/ Cip1). Am J Physiol Cell Physiol. 2004;287(6):C1541-6. doi:10.1152/ ajpcell.00025.2004.

49. Yoshinaga H, Matsuhashi S, Fujiyama C, Masaki Z. Novel human PDCD4 (H731) gene expressed in proliferative cells is expressed in the small duct epithelial cells of the breast as revealed by an anti-H731 antibody. Pathol Int. 1999:49(12):1067-77.

50. Kakimoto T, Shiraishi R, Iwakiri R, Fujimoto K, Takahashi H, Hamajima $\mathrm{H}$, et al. Expression patterns of the tumor suppressor PDCD4 and correlation with beta-catenin expression in gastric cancers. Oncol Rep. 2011;26(6):1385-92. doi:10.3892/or.2011.1450.

\section{Submit your next manuscript to BioMed Central and we will help you at every step:}

- We accept pre-submission inquiries

- Our selector tool helps you to find the most relevant journal

- We provide round the clock customer support

- Convenient online submission

- Thorough peer review

- Inclusion in PubMed and all major indexing services

- Maximum visibility for your research

Submit your manuscript at www.biomedcentral.com/submit
( ) BioMed Central 